\title{
ALFRED L. COPLEY
}

\section{June 1910 - 27 January 1992}

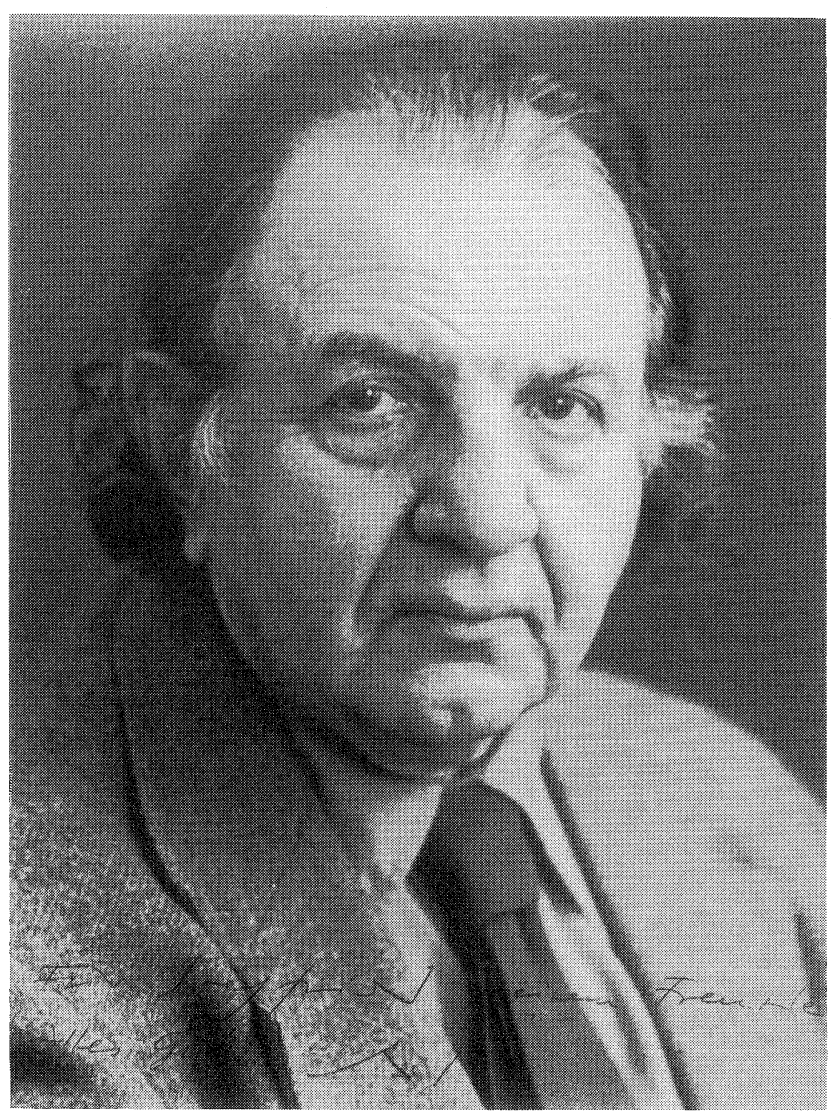

We are deeply saddened by the untimely sudden death of Alfred L. Copley, the founder of our journal CLINICAL HEMORHEOLOGY. He died in New York City during the night to 28 January 1992 in consequence of kidney carcinoma metastases. Even the very last phase of his life he dedicated to his lifework and on 31 December 1991, his many friends and admirers were informed 
of the completion of the book entitled "ONE MAN TWO VISIONS L. Alcopley - A.L. Copley Artist and Scientist", compiled by Alex Silberberg, in press at Pergamon Press. The book comprises contributions from 103 authors to his life as artist and scientist, numerous reflections and reminiscences from and about him and also a great number of personally selected reproductions of his paintings. This work will now be and will always remain a notable memorial to A.L. Copley.

A detailed curriculum vitae with bibliography can be found by our readers in the Eestschrift "Perspectives in Biorheology", dedicated to His seventieth Birthday, which appeared in Biorheology 18, 305-729 (1981). It was supplemented and continued in: A.L. Copley: "The History of Clinical. Hemorheology", Clin. Hemorheol. 5, 765-812 (1985).

As mentioned in the Editorial, the present issue was dedicated to our friend A.L. Copley and the two subsequent articles were published as a tribute to our journal's founder and Executive Editor of many years on the occasion of the transfer of the journal's Executive Editorial office from New York to Karlsruhe. It seems incredible to us that due to his unexpected death they have now turned into obituaries.

Alfred L. Copley's plans for the future were full of activities as artist and scientist. These activities of a wonderful person will be greatly missed by all his friends. He will be remembered with love and honour and live on through his artistic and scientific work. 